\title{
Anemia management after acute brain injury
}

\author{
Christophe Lelubre ${ }^{1,2}$, Pierre Bouzat ${ }^{3,4}$, Ilaria Alice Crippa ${ }^{1}$ and Fabio Silvio Taccone ${ }^{1 *}$
}

\begin{abstract}
Anemia is frequent among brain-injured patients, where it has been associated with an increased risk of poor outcome. The pathophysiology of anemia in this patient population remains multifactorial; moreover, whether anemia merely reflects a higher severity of the underlying disease or is a significant determinant of the neurological recovery of such patients remains unclear. Interestingly, the effects of red blood cell transfusions (RBCT) in moderately anemic patients remain controversial; although hemoglobin levels are increased, different studies observed only a modest and inconsistent improvement in cerebral oxygenation after RBCT and raised serious concerns about the risk of increased complications. Thus, considering this "blood transfusion anemia paradox", the optimal hemoglobin level to trigger RBCT in brain-injured patients has not been defined yet; also, there is insufficient evidence to provide strong recommendations regarding which hemoglobin level to target and which associated transfusion strategy (restrictive versus liberal) to select in this patient population. We summarize in this review article the more relevant studies evaluating the effects of anemia and RBCT in patients with an acute neurological condition; also, we propose some potential strategies to optimize transfusion management in such patients.
\end{abstract}

Keywords: Red blood cell transfusion, Threshold, Anemia, Traumatic brain injury, Subarachnoid hemorrhage

\section{Background}

Anemia is a frequent condition among critically ill patients [1] and appears early during their hospital course. In a European, multicenter study on 3534 patients, $63 \%$ of those newly admitted to the intensive care unit (ICU) had hemoglobin $(\mathrm{Hb})$ levels below $12 \mathrm{~g} / \mathrm{dl}$ on admission; in particular, $29 \%$ of them had $\mathrm{Hb}$ values below $10 \mathrm{~g} / \mathrm{dl}$ [2]. Overall, $37 \%$ of these 3534 patients received at least one red blood cell transfusion (RBCT) during their ICU stay. Interestingly, during the first 28 days, $\mathrm{Hb}$ levels tended to reach $10 \mathrm{~g} / \mathrm{dl}$ on average regardless of the initial $\mathrm{Hb}$ value or the occurrence of bleeding events. In another study on 4892 ICU patients in which $44 \%$ received at least one RBCT after a median of 3 days, an $\mathrm{Hb}$ level below $9 \mathrm{~g} / \mathrm{dl}$ was associated with poorer outcomes whereas the amount of RBCT transfused was also associated with increased ICU length of stay and mortality [3].

\footnotetext{
* Correspondence: ftaccone@ulb.ac.be

'Department of Intensive Care, Hôpital Erasme, Université Libre de Bruxelles (ULB), Route de Lennik 808, 1070 Brussels, Belgium

Full list of author information is available at the end of the article
}

The pathophysiology of anemia in critically ill patients remains multifactorial and has been compared to the so-called "anemia of chronic illness"; as such, apart from evident causes such as primary blood losses (e.g., trauma, surgery, gastrointestinal bleeding), multiple other etiologies contribute and often coexist in the same patient [4]. These include, amongst others, blood losses related to minor procedures or phlebotomy, hemodilution secondary to fluid resuscitation, altered red blood cell (RBC) production, and reduced RBC half-life [5-7].

Although it is associated with poor outcome, whether anemia exerts deleterious consequences on brain function in various pathological conditions remains a matter of debate. In neurological circumstances such as severe traumatic brain injury (TBI) or stroke, Hb level is a primary determinant of brain oxygenation and, in a recent study, anemia was an independent predictor of mortality among patients suffering from an acute ischemic stroke $[8,9]$.

In this article, we summarize the literature evaluating the effects of anemia and RBCT in patients with an acute neurological condition as well as potential strategies to optimize $\mathrm{Hb}$ management in such patients. 


\section{Effects of anemia on the brain}

Oxygen delivery $\left(\mathrm{DO}_{2}\right)$ to the brain is directly proportional to cerebral blood flow (CBF) and arterial oxygen content $\left(\mathrm{CaO}_{2}\right)$ and, therefore, also to $\mathrm{Hb}$ levels according to the equation:

$$
\mathrm{DO}_{2}=\mathrm{Q} \times \mathrm{CaO}_{2}
$$

where $\mathrm{Q}$ indicates blood flow and $\mathrm{CaO}_{2}=\mathrm{Hb} \times \mathrm{SaO}_{2} \times$ $1.39\left(\mathrm{SaO}_{2}\right.$ indicates arterial oxygen saturation). According to this equation, a significant reduction of $\mathrm{Hb}$ may lead to decreased brain $\mathrm{DO}_{2}$ and eventually tissue hypoxia if the compensatory mechanisms aiming to keep a constant tissue oxygenation fail or are overtaken [10]. In the setting of normovolemic anemia, these mechanisms include the activation of carotid and aortic chemoreceptors and, hence, of the sympathetic tone, which lead to a rise in heart rate and left ventricular stroke volume, resulting in increased cardiac output and CBF [11]. Oxygen extraction is also increased at the microcirculatory level [12]. Moreover, anemia is associated with reduced blood viscosity, which promotes venous return and decreases the resistance to systemic flow as well as reduces endothelial shear stress, resulting in an improved microvascular perfusion $[13,14]$.

In this setting, cerebral vasodilation is promoted by enhanced production of nitric oxide (NO) by perivascular neurons and endothelial cells [15]. This results in an increased $\mathrm{CBF}$ that maintains a constant cerebral $\mathrm{DO}_{2}$. Importantly, according to Poiseuille's equation showing that blood flow is proportional to the vessel radius to the fourth power, small changes in vascular diameter will have a large influence on CBF. The role of NO in regulating CBF during anemia is extremely complex: cerebral hypoxic vasodilatation can be altered by $\mathrm{NO}$ synthase (NOS) inhibitors through a direct effect on neuronal NOS (nNOS) [15], while expression of endothelial NO synthase (eNOS) is increased by increased capillary shear stress [16]. Finally, oxyhemoglobin is also able to transport NO; following oxygen release from oxyhemoglobin, structural changes in heme conformation could promote NO release and further promote local vasodilation in territories with high oxygen extraction [10]. Interestingly, cerebral hypoxia secondary to severe anemia would also induce the production of the transcription factor hypoxiainducible factor (HIF), an heterodimer composed of two subunits (HIF- $1 \alpha$ and HIF-1 $\beta$ ) which plays an important role in the protection of brain cells from ischemia [17]. Moreover, HIF also promotes the secretion of erythropoietin (EPO), which negatively regulates neuronal apoptosis and seems to exert some neuroprotective effects through specific receptors expressed within cerebral tissue [18], and of vascular endothelial growth factor, which stimulates angiogenesis and allows long-term adaptations to tissue hypoxia [19].
Overall, these adaptation mechanisms maintain $\mathrm{DO}_{2}$ during anemia in healthy conditions, at least until a critical $\mathrm{Hb}$ threshold below which tissue hypoxia and altered brain function may develop. As such, in healthy volunteers submitted to progressive normovolemic anemia, some authors observed increasing fatigue and cognitive disorders (short- and long-term memory disturbances) when $\mathrm{Hb}$ levels fell to $5 \mathrm{~g} / \mathrm{dl}$; these symptoms were rapidly reversed after autologous RBCT [14, 20]. In healthy subjects, however, acute normovolemic anemia (to $\mathrm{Hb}$ levels of $5.1 \pm 0.3 \mathrm{~g} / \mathrm{dl}$ ) was not associated with increased somatosensory-evoked potential latencies, suggesting brain dysfunction [21]. These findings underline that a progressive reduction of $\mathrm{Hb}$ in the normal brain can be compensated by an increase in CBF due to cerebral vasodilation until a critical $\mathrm{Hb}$ level around $5-6 \mathrm{~g} / \mathrm{dl}$, when cerebral $\mathrm{DO}_{2}$ will be progressively reduced as no further vasodilation can occur and maximal $\mathrm{CBF}$ values are obtained (Fig. 1). Nevertheless, these data on healthy volunteers may not directly translate to brain-injured patients. First, $\mathrm{Hb}$ levels in these critically ill patients are generally higher than those used in the aforementioned studies [22]. Second, some of these brain-injured patients may develop hemodynamic instability or acute heart failure, which would significantly impair the compensatory increase in cardiac output to provide adequate cerebral oxygenation during anemia [23]. Third, anemia-induced vasodilation may be limited by other ongoing compensatory mechanisms to maintain adequate brain perfusion induced by the acute brain injury itself, so that the "cerebrovascular reserve", i.e., the capability of brain vasculature to vasodilate in response to different stimuli (including changes in mean arterial pressure, arterial carbon dioxide tension $\left(\mathrm{PaCO}_{2}\right)$, or reduced $\mathrm{DO}_{2}$ ), is significantly limited when compared with healthy subjects [24]. This could promote brain tissue hypoxia at hemoglobin levels higher than the hemoglobin thresholds observed in healthy volunteers [25]. Finally, brain lesions observed after TBI or a stroke may be highly heterogeneous; some territories defined as "penumbra" zones (e.g., moderately ischemic tissue lying between tissue that is normally perfused and an infarcted area) exist, where oxygen supply may become inadequate to satisfy oxygen demand in the case of anemia. Thus, in the injured brain, a lower CBF compared with the normal brain is observed for similar $\mathrm{Hb}$ values (Fig. 2). As the "cerebrovascular reserve" is compromised in this setting, maximal vasodilation may occur at $\mathrm{Hb}$ levels around $8-9 \mathrm{~g} / \mathrm{dl}$ and any further decrease in $\mathrm{Hb}$ below this threshold may contribute to reduced cerebral $\mathrm{DO}_{2}$.

\section{Effects of anemia on the injured brain Traumatic brain injury}

Several studies have shown an association between anemia and poor outcome after TBI [26-28]. In two 


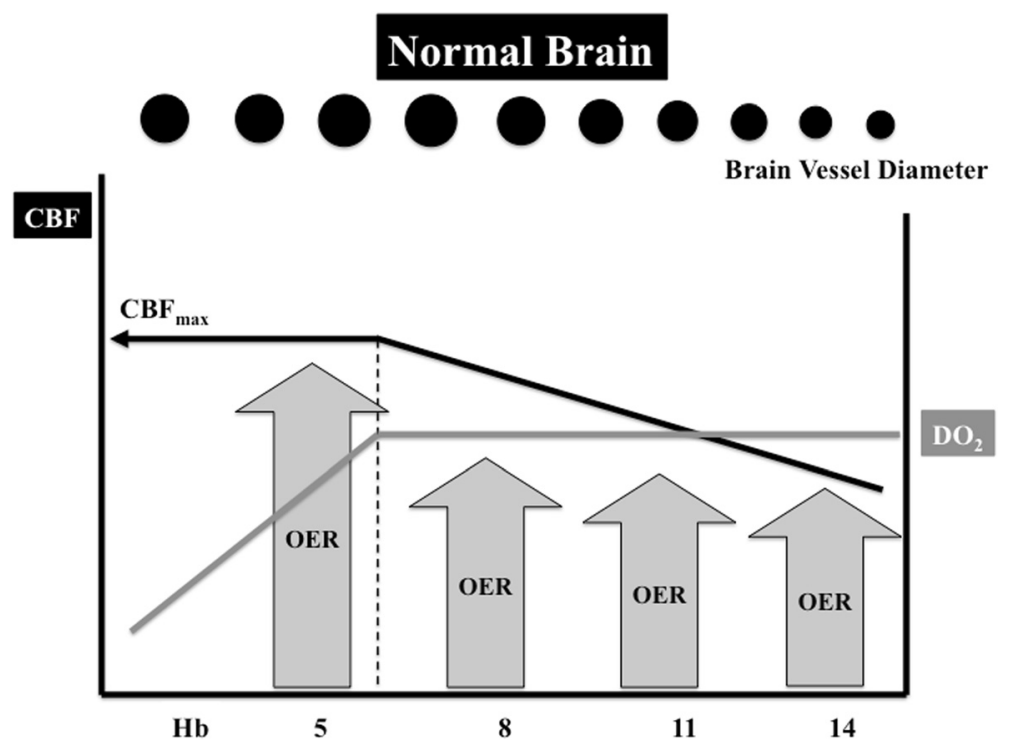

Fig. 1 In the normal brain, a progressive reduction of hemoglobin $(\mathrm{Hb})$ is compensated for by vasodilation, which results in increased cerebral blood flow (CBF, black line) and a constant cerebral oxygen delivery $\left(\mathrm{DO}_{2}\right.$, grey line). When $\mathrm{Hb}$ falls below $5-6 \mathrm{~g} / \mathrm{dl}, \mathrm{DO}_{2}$ is progressively reduced; no further vasodilation can occur and maximal CBF values $\left(C B F_{\text {max }}\right)$ are obtained. The oxygen extraction rate $(O E R)$ then increases to meet metabolic tissue requirements

post hoc analyses including more than 3500 patients with severe TBI (defined as a Glasgow Coma Scale score $<9)$, low $\mathrm{Hb}$ levels were significantly associated in a logistic regression model with poor neurological outcome at 3 and 6 months after the initial insult $[28,29]$. In a retrospective study on 1150 patients with TBI, anemia (defined as an $\mathrm{Hb}$ level below $9 \mathrm{~g} / \mathrm{dl}$ ) was significantly associated with increased mortality (adjusted odds ratio (OR) 3.67, 95 \% confidence interval (CI) 1.13-2.24) [26]. In another retrospective study on 169 patients with TBI, an average $\mathrm{Hb}$ level below $9 \mathrm{~g} / \mathrm{dl}$ over a period of 7 days was associated, in a multivariate analysis, with increased

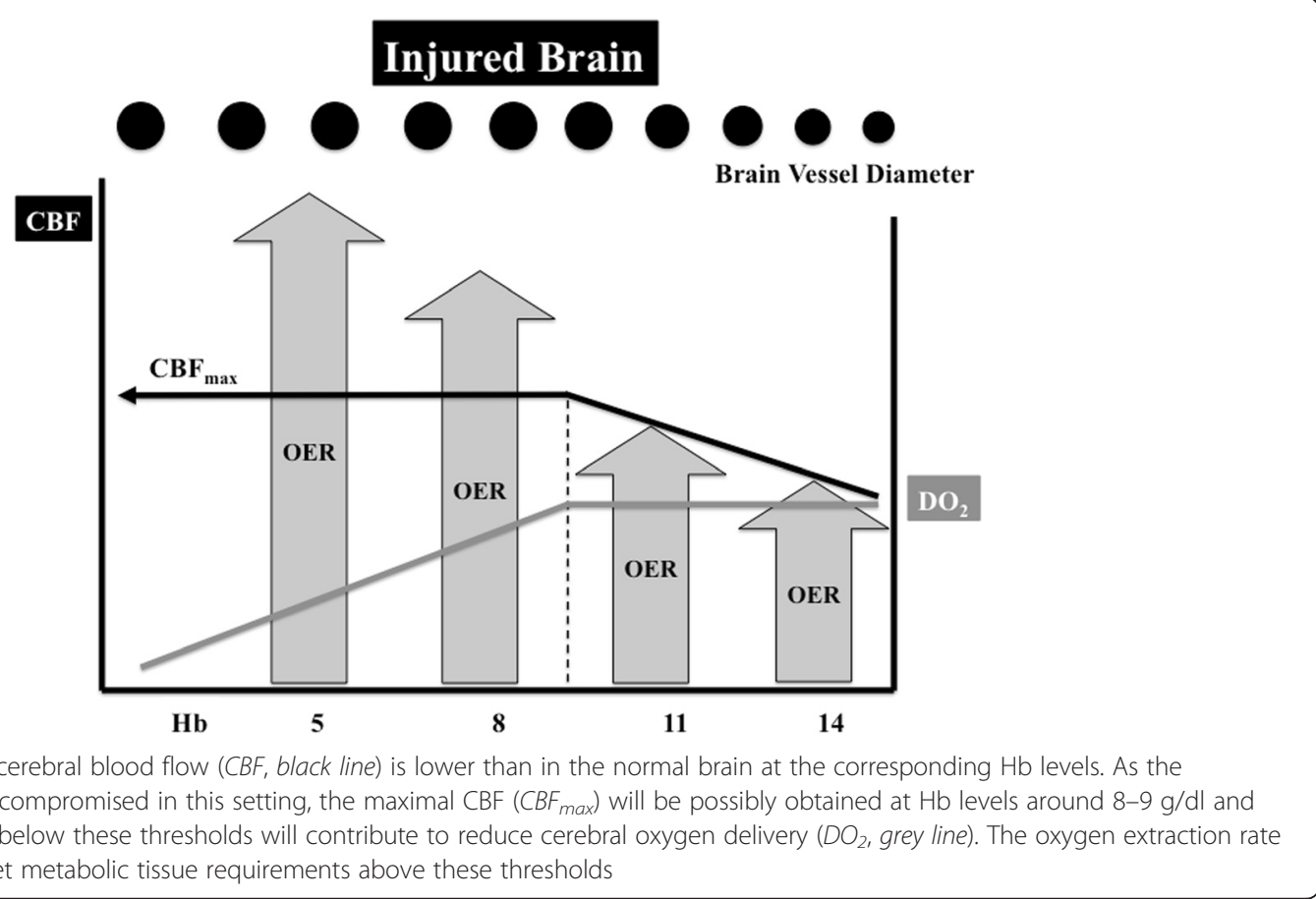


hospital mortality (relative risk 3.1, 95 \% CI 1.5-6.3; $p=$ 0.03) [27]. Similar observations were found in two other studies [30,31], although the evaluation of anemia and poor outcome after TBI did not consistently demonstrate harm in others [32-34]. Unfortunately, these studies generally had important methodological weaknesses. Most of them were retrospective, which may have reduced the collection of variables potentially influencing outcome. Also, anemia was defined according to different cutoffs, thus limiting comparison among all the different cohorts of patients. Also, only one single $\mathrm{Hb}$ measurement was considered in the definition of anemia, while the exposure of an injured brain to prolonged periods of low $\mathrm{Hb}$ levels may be more relevant. As an example, in 116 patients with severe TBI, Griesdale et al. [35] observed that a Hb time curve above $9 \mathrm{~g} / \mathrm{dl}$ was associated with improved neurological outcome independent of the administration of RBCT. Finally, the primary outcome evaluating the relationship between anemia and outcome was mortality in some studies while others focused on long-term neurological recovery [36].

Furthermore, anemia has also been associated with changes in brain metabolism or oxygenation. As such, Sahuquillo et al. [37] showed that, in 28 patients with severe $\mathrm{TBI}$, low $\mathrm{Hb}$ levels were one of the most important predictors of the development of ischemic areas, as suggested by increased arterio-jugular oxygen $\left(\mathrm{AJDO}_{2}\right)$ and lactate differences. Similarly, Cruz et al. [38] evaluated the cerebral metabolic rate of oxygen consumption $\left(\mathrm{CMRO}_{2}\right)$ in TBI patients with anemia and found that a decrease of $\mathrm{Hb}$ was associated with a decrease in $\mathrm{CMRO}_{2}$ independent of the level of consciousness of patients. However, anemia (defined as $\mathrm{Hb}<11 \mathrm{~g} / \mathrm{dl}$ in at least three measurements) was associated with a marked decrease in $\mathrm{AJDO}_{2}$ in only $9 \%$ of the observations in another study [39], suggesting that global cerebral ischemia is a rare finding in acute brain injury with anemia. More recently, in a retrospective analysis of 474 simultaneous measures of $\mathrm{Hb}$ and brain oxygen tension $\left(\mathrm{PbtO}_{2}\right)$ in $80 \mathrm{TBI}$ patients, only $\mathrm{Hb}$ levels $<9 \mathrm{~g} / \mathrm{dl}$ were significantly associated with a low value of $\mathrm{PbtO}_{2}(<20 \mathrm{mmHg})$. In this study, anemia combined with low $\mathrm{PbtO}_{2}$ was associated with poor neurological outcome (Glasgow Outcome Scale of 1-3 at 30 days), whereas isolated anemia was not [40]. Association between anemia and low $\mathrm{PbtO}_{2}$ was, however, not found in all studies [41].

\section{Subarachnoid hemorrhage}

In several studies including patients suffering from subarachnoid hemorrhage (SAH), anemia was an independent risk factor for poor neurological outcome [42, 43]. In a retrospective study on 580 patients with $\mathrm{SAH}$, anemia was an independent risk factor for mortality and neurological disability at 3 months, even after correction for confounders (OR 1.8, $95 \%$ CI 1.1-2.9, $p=0.02$ ) [44]. In another retrospective study $(n=245)$, Hb below $10 \mathrm{~g} / \mathrm{dl}$ was associated with poorer outcomes, including mortality, severe disability, and the development of delayed cerebral ischemia [45]. Conversely, in a large cohort of SAH patients $(n=611)$, higher $\mathrm{Hb}$ levels were found in patients with good outcome compared with those with poor outcome (11.7 \pm 1.5 versus $10.9 \pm 1.2 \mathrm{~g} / \mathrm{dl}, p<0.001)$ [46]; also, the highest $\mathrm{Hb}$ values over the ICU stay were an independent predictor of good neurological recovery at 3 months.

As for studies on TBI, the effects of anemia on brain metabolism have also been evaluated in SAH patients. In a prospective study on 20 patients with poor-grade $\mathrm{SAH}$, $\mathrm{Hb}$ levels below $9 \mathrm{~g} / \mathrm{dl}$ were associated with an increased risk of low $\mathrm{PbtO}_{2}$ values $(<20 \mathrm{mmHg})$ and altered metabolism (e.g., increased lactate to pyruvate ratio (LPR) above 40 when assessed using cerebral microdialysis catheters), suggesting ongoing anaerobiosis in the absence of adequate cerebral $\mathrm{DO}_{2}$ [47]. Also, in a retrospective analysis of 359 different measurements performed in $34 \mathrm{SAH}$ patients, $\mathrm{Hb}$ levels below 9-10 $\mathrm{g} / \mathrm{dl}$ were independent predictors of tissue hypoxia (e.g., elevated LPR) compared with higher $\mathrm{Hb}$ levels [48].

\section{Other forms of brain injury}

Anemia on admission has been found to be among the most significant predictors of short- and long-term poor outcome in patients with acute ischemic stroke [49]. In young patients suffering from acute stroke due to cervical artery dissection $(n=1206)$, anemia (defined as $\mathrm{Hb}<12 \mathrm{~g} / \mathrm{dl}$ ) was found in $7 \%$ of them on admission and was associated with the severity of stroke and unfavorable neurological outcome [50]. In another study, anemia on admission (identified as an hematocrit value less than $30 \%$ ) was associated with poor outcome in patients with less severe stroke, defined as a National Institutes of Health Stroke Scale score of $<10$ [51]. Nevertheless, mild anemia could worsen patients' functional status also when occurring in the sub-acute phase of stroke [52]. Also, decreasing $\mathrm{Hb}$ levels after admission could independently predict infarct growth in stroke patients treated with intravenous thrombolysis [53]. In contrast, in a recent retrospective study, Hb concentrations higher than the normal limits on admission were also associated with greater disability at discharge and 30-day mortality, even after adjustment for major potential confounders, after ischemic stroke [54].

In one retrospective study, anemia on admission was identified in $19 \%$ of patients with a non-traumatic intracranial hemorrhage (ICH) and was found to be an independent predictor of long-term mortality [55]. Also, lower $\mathrm{Hb}$ levels $(<12 \mathrm{~g} / \mathrm{dl})$ were found in $23 \%$ of $2406 \mathrm{ICH}$ patients during their hospital stay, including $4 \%$ with 
$\mathrm{Hb}<10 \mathrm{~g} / \mathrm{dl}$ [56]. Patients with anemia were more likely to have severe neurological deficits on admission, in particular when $\mathrm{ICH}$ was not associated with the use of anticoagulants. $\mathrm{Hb}$ below $10 \mathrm{~g} / \mathrm{dl}$ was also associated with poor outcome and increased 1-year mortality. Similar results were also found in other studies $[57,58]$. Interestingly, anemia was also a predictor of larger hematoma volumes in these patients [59].

Among patients suffering from post-anoxic brain injury, Ameloot et al. [60] found a strong linear relationship between $\mathrm{Hb}$ and cerebral brain oxygen saturation $\left(\mathrm{StO}_{2}\right)$, assessed by non-invasive near-infrared spectroscopy. Moreover, $\mathrm{Hb}$ levels below $10 \mathrm{~g} / \mathrm{dl}$ generally resulted in low $\mathrm{StO}_{2}$ values, while $\mathrm{Hb}$ values above $12.3 \mathrm{~g} / \mathrm{dl}$ were associated with better outcome, particularly in patients with $\mathrm{StO}_{2}$ values $<62 \%$.

\section{Efficacy of RBCT in patients with acute brain injury}

Considering the frequent association of anemia and poor outcome after an acute brain injury, current recommendations on the use of a restrictive transfusion strategy in ICU patients (transfusion if $\mathrm{Hb}$ levels $<7 \mathrm{~g} / \mathrm{dl}$ in the absence of severe cardiac comorbidities) [61] may not apply to patients with brain injuries. One may argue that RBCT to increase $\mathrm{Hb}$ levels above $9-10 \mathrm{~g} / \mathrm{dl}$ in these patients would be a logical therapeutic decision to reduce the risk of tissue hypoxia and potentially improve patient outcome. Nevertheless, the benefits of RBCT should always be weighed against the risk of a transfusionrelated complication; as such, $\mathrm{RBCT}$ was associated with increased mortality and a higher occurrence of organ dysfunction among critically ill patients, although this has been observed only in observational studies [62]. The pathophysiology of such complications is complex and is related to several pathways, including immune modulation [63], risk of circulatory overload [64] or acute lung injury [65], altered RBC function due to prolonged storage [66], or impaired peripheral microcirculation due to NO scavenging and reduced deformability [67].

\section{Severe traumatic brain injury}

In some recent studies on patients with severe TBI, the increase in $\mathrm{PbtO}_{2}$ after RBCT was generally small [68-71]; moreover, $\mathrm{RBCT}$ was associated with a decreased $\mathrm{PbtO}_{2}$ in some subjects. These studies included no clear prediction criteria to distinguish between "responders" and "non-responders" (on the basis of $\mathrm{PbtO}_{2}$ changes) to RBCT [69, 71]. Even if RBCT could produce an improvement in cerebral oxygenation, this was not always accompanied by significant changes in cerebral metabolism, e.g., reduction in LPR [71].

Alternatively, studies evaluating RBCT as a predictor of good outcome after TBI have found inconsistent results, although some of them suggested detrimental effects
[43]. In a large retrospective study on 1150 TBI patients in which $46 \%$ of patients received RBCT when Hb levels were below $9 \mathrm{~g} / \mathrm{dl}$, Salim et al. [26] found that RBCT was associated with an increased hospital mortality in a logistic regression model (adjusted OR 2.19, 95 \% CI 1.27-3.75, $p=0.004$ ), while anemia was not. In another retrospective study on 139 anemic patients (hematocrit between 21 and $30 \%$ ) with TBI, RBCT was an independent risk factor for poor neurological outcome at 3 and 6 months [70]. Other studies did not confirm these findings. In a small retrospective study of 82 TBI patients with moderate anemia ( $\mathrm{Hb}$ between 8 and $10 \mathrm{~g} / \mathrm{dl}$ ), there was no association between RBCT and poor neurological outcome and mortality was similar between anemic patients (Hb between 8 and $10 \mathrm{~g} / \mathrm{dl}$ ) who received RBCT and those who didn't [68].

\section{Subarachnoid hemorrhage}

Several studies on patients with SAH found an association between RBCT and worse neurological outcome or even increased mortality [43, 72-74]. In a retrospective study on 245 patients with SAH, RBCT was associated, in a multivariate analysis, with an increased risk of composite endpoint, including mortality, severe disability, or delayed cerebral ischemia (OR 4.3, 95 \% CI 1.5-9.3, $p<0.01$ ), as well as the occurrence of more nosocomial infections [45]. However, these findings were not confirmed in all studies. In a study on $292 \mathrm{SAH}$ patients, the authors found no association between RBCT and increased mortality or poor neurological outcome in a multivariate analysis [75].

Few studies have evaluated the impact of RBCT on brain oxygenation in poor-grade SAH patients. In one study on 35 neuro-critically ill patients (including 12 with $\mathrm{SAH}$ ) receiving RBCT (2 units on average; mean $\mathrm{Hb}$ threshold for RBCT of $8.7 \mathrm{~g} / \mathrm{dl}$ ), Smith et al. [69] observed only a modest increase in $\mathrm{PbtO}_{2}(3.2 \mathrm{mmHg})$ and no relationship between the increase in $\mathrm{PbtO}_{2}$ and baseline values of cerebral oxygenation; importantly, in nine patients, $\mathrm{PbtO}_{2}$ decreased after RBCT. In another study, Kurtz et al. [76] showed that each $1.0 \mathrm{~g} / \mathrm{dl}$ increase in $\mathrm{Hb}$ levels after RBCT in poor-grade SAH patients was associated with an increase in $\mathrm{PbtO}_{2}$ of $1.39 \mathrm{mmHg}$, without significant effects on cerebral LPR. In a prospective study on eight anemic SAH patients (baseline hemoglobin $8.7 \mathrm{~g} / \mathrm{dl}$ ) in whom a cerebral positron emission tomography (PET) was performed, the administration of 1 unit of RBC resulted in a significant increase in brain $\mathrm{DO}_{2}$; these effects were independent of $\mathrm{CBF}$ and related to a higher $\mathrm{CaO}_{2}$ [77]. In this study, $\mathrm{CMRO}_{2}$ remained globally unchanged but there was a significant decrease in oxygen extraction ratio, in particular in cerebral territories with the lowest baseline $\mathrm{DO}_{2}$. To confirm that these data were not secondary to the hemodynamic 
effects (e.g., increased cardiac output or mean arterial pressure through fluid expansion) of RBCT, the same authors evaluated brain $\mathrm{DO}_{2}$ in three subgroups of poor-grade $\mathrm{SAH}$ patients (nine receiving a fluid bolus, 12 receiving phenylephrine to raise mean arterial pressure without clear vasospasm, 17 receiving one RBCT in case of $\mathrm{Hb}<11 \mathrm{~g} / \mathrm{dl}$-baseline $\mathrm{Hb}$ of $9.1 \pm 1.2 \mathrm{~g} / \mathrm{dl}$ ) [78]. Regional cerebral $\mathrm{DO}_{2}$ significantly increased in the three groups but the effects were more important in patients receiving $\mathrm{RBCT}$; however, the proportion of patients with low $\mathrm{DO}_{2}$ was decreased only among patients treated with vasopressors or RBCT, showing the more relevant improvement in global cerebral oxygenation.

\section{Other forms of brain injury}

Outcomes in $\mathrm{ICH}$ patients receiving $\mathrm{RBCT}$ have been contradictory. In 546 consecutive patients with $\mathrm{ICH}$, RBCT was administered to 100 patients (18\%) during their hospital stay; in multivariable analysis, RBCT was associated with improved survival at 30 days (OR 2.76, $95 \%$ CI 1.45-5.26, $p=0.002$ ) [79]. A recent retrospective study failed to demonstrate an improvement in outcomes with $\mathrm{RBCT}$ in patients with ICH [80]. Also, in another study, RBCT was not an independent predictor of improved neurological outcome [81].

Very few data are available on the effects of RBCT on the outcome of patients with ischemic stroke. A recent retrospective study showed that one-third of anemic $(\mathrm{Hb}<12 \mathrm{~g} / \mathrm{dl})$ patients received at least one RBCT at the discretion of the attending physician; although anemia was associated with a longer length of ICU stay and duration of mechanical ventilation requirements, no significant benefit from RBCT was found and no specific transfusion strategies were recommended in this patient population [82].

\section{Which is the optimal transfusion strategy for patients with acute brain injury?}

Only a few studies have compared the effects of two different transfusion strategies on the outcome of patients with an acute brain injury. In a subgroup analysis of the multicenter randomized Transfusion Requirements in Critical Care (TRICC) trial on 67 patients with TBI, patients randomized to the "restrictive" RBCT policy (e.g., $\mathrm{Hb}$ of $7.0 \mathrm{~g} / \mathrm{dl}$ to initiate $\mathrm{RBCT}, n=29$ ) received less RBC units than those included in the "liberal" strategy ( $\mathrm{Hb}$ of $10.0 \mathrm{~g} / \mathrm{dl}$ to initiate RBCT, $n=38$ ), with a similar 30 -day mortality (17 versus $13 \%, p=0.64$ ), hospital length of stay, and development of multiple organ dysfunction [32]. In the subgroup of 66 children with different types of brain injury included in the Transfusion Requirements in the Pediatric Intensive Care Unit (TRIPICU) study, patients were randomized to receive $\mathrm{RBCT}$ for an $\mathrm{Hb}$ threshold of 7 or $9.5 \mathrm{~g} / \mathrm{dl}$ [83]; the mortality rate was very low $(3 / 66)$ and similar between the two groups. In a retrospective study, TBI patients receiving RBCT and who could not reach an $\mathrm{Hb}$ target of at least $9.3 \mathrm{~g} / \mathrm{dl}$ at the end of the initial surgery showed a higher early mortality than others (17/37 (46\%) versus 34/102 (33\%)) [84]. After adjustment for confounders, however, no significant impact of transfusions was found on patient outcome and the difference in mortality was lost after 4 weeks. In two other retrospective studies on TBI $[68,70]$ including more than 200 patients, patients receiving at least one RBCT were compared with those who were not transfused for a specific range of $\mathrm{Hb}$ between 7 and $10 \mathrm{~g} / \mathrm{dl}$; no significant effect on outcome was observed.

Only two prospective randomized trials have been conducted specifically in brain-injured patients. In the first study, Naidech et al. [85] randomized 44 SAH patients at high risk of vasospasm to receive RBCT for a target $\mathrm{Hb}$ of 10 or $11.5 \mathrm{~g} / \mathrm{dl}$; more transfusions were observed in the high $\mathrm{Hb}$ threshold group than in the other, while safety endpoints (e.g., infections and thromboembolic events) were not different between the groups. The numbers of cerebral infarctions on cerebral magnetic resonance imaging (MRI; 6/20 versus 9/22) and of patients showing a poor neurological recovery were lower, although not statistically significant, in the higher $\mathrm{Hb}$ threshold group. Nevertheless, the primary outcome of this study was the safety of two different RBCT policies and the limited cohort of patients precluded any further analysis of the impact of $\mathrm{Hb}$ levels on neurological outcome. In the second study, Robertson et al. [86] investigated the effects of two different thresholds of $\mathrm{Hb}$ to guide RBCT (7 versus $10 \mathrm{~g} / \mathrm{dl}$ ) in patients suffering from TBI in a factorial design including also the administration of erythropoietin (EPO) or placebo. On a total of 200 patients, favorable outcome (dichotomized Glasgow Outcome Scale at 6 months) was similar between patients included in the $7 \mathrm{~g} / \mathrm{dl}(37 / 87,43 \%)$ or in the $10 \mathrm{~g} / \mathrm{dl}(31 /$ 94, $33 \%$ ) group , although patients maintained relatively high median $\mathrm{Hb}$ levels in both groups throughout the study (between 9.7 and $10.8 \mathrm{~g} / \mathrm{dl}$ in the "restrictive" transfusion strategy versus 11.0 and $11.5 \mathrm{~g} / \mathrm{dl}$ in the "liberal" strategy). This study showed that there was no significant benefit in maintaining high $\mathrm{Hb}$ levels in patients suffering from severe TBI. Moreover, thromboembolic events were significantly more frequent in the group transfused at $10 \mathrm{~g} / \mathrm{dl}(22 / 101$ (22 \%) versus 8/99 (8 \%), $p=0.009)$.

\section{Practices}

Two surveys have been published to determine whether physician specialty influences transfusion threshold in patients with TBI or SAH. In the first study, trauma surgeons, neurosurgeons, and ICU physicians from 187 level I trauma centers in the United States were asked to indicate their $\mathrm{Hb}$ threshold to initiate $\mathrm{RBCT}$ in two 
clinical scenarios referring to a patient with severe TBI either with or without intracranial hypertension [87]. The response rate was $58 \%$; neurosurgeons used a greater mean $\mathrm{Hb}$ threshold to initiate $\mathrm{RBCT}$ than trauma surgeons and ICU physicians whether the intracranial pressure was normal or elevated. Moreover, neurosurgeons used less indicators of poor anemia tolerance, such as increased lactate, low mixed venous saturation, or $\mathrm{PbtO}_{2}$, than the others to decide on RBCT. In a second study conducted in North America, neuro-intensivists, vascular neurosurgeons, and multidisciplinary intensivists working in academic hospitals were questioned on the common triggers to initiate RBCT in SAH patients [88]. More than half of the clinicians (282/531) eventually responded. Mean $\mathrm{Hb}$ concentrations at which clinicians administered RBCT significantly increased from a good-grade $\mathrm{SAH}$ patient to a poor-grade one (7.8 versus $8.2 \mathrm{~g} / \mathrm{dl}$ ), in particular in the case of cerebral vasospasm and delayed cerebral ischemia. Opinions covered a broad range in each setting. Neurosurgeons expressed higher minimum $\mathrm{Hb}$ goals than ICU physicians to initiate RBCT. The presence of low $\mathrm{PbtO}_{2}(<15 \mathrm{mmHg})$ and high LPR $(>40)$ were also important triggers to administer RBCT.

\section{A practical approach}

Several observational studies have shown that anemia, even if defined with different $\mathrm{Hb}$ thresholds, was associated with worse neurological outcome and increased mortality rate after TBI, SAH, and other forms of brain injury. Whether anemia merely reflects a higher severity of the underlying disease, a longer ICU length of stay and other ongoing processes (e.g., active bleeding, sepsis, surgical procedures), or can directly affect the neurological recovery of such patients remains unclear. Interestingly, the effects of transfusions to increase $\mathrm{Hb}$ levels in moderately anemic patients remain controversial, with a modest and inconsistent increase in brain oxygenation after RBCT and serious concerns about the risk of increased mortality. Thus, considering this "blood transfusion anemia paradox", the optimal $\mathrm{Hb}$ level to trigger RBCT in brain-injured patients has not yet been defined. There is no strong evidence to support targeting a $\mathrm{Hb}$ concentration greater than $7 \mathrm{~g} / \mathrm{dl}$ or a liberal transfusion strategy in this patient population. Importantly, it should be better evaluated whether alternative strategies to RBCT might be considered in this setting to avoid a significant decrease of $\mathrm{Hb}$ levels below critical thresholds to ensure adequate brain oxygenation.

According to what has been proposed for other critically ill patients, a "restrictive" transfusion practice should be considered safe for brain-injured patients who are awake and can undergo repeated clinical examination (Fig. 3). In these patients, RBCT should be administered to maintain $\mathrm{Hb}$ levels of at least $7.0 \mathrm{~g} / \mathrm{dl}$ [89]. In case of neurological deterioration or in poor-grade patients, the decision to initiate RBCT should then be individualized to some specific triggers suggesting a poor tolerance to anemia (e.g., ischemic heart disease) or global/cerebral tissue hypoxia, which may be secondary or at least enhanced by reduced Hb levels. Regarding "systemic"

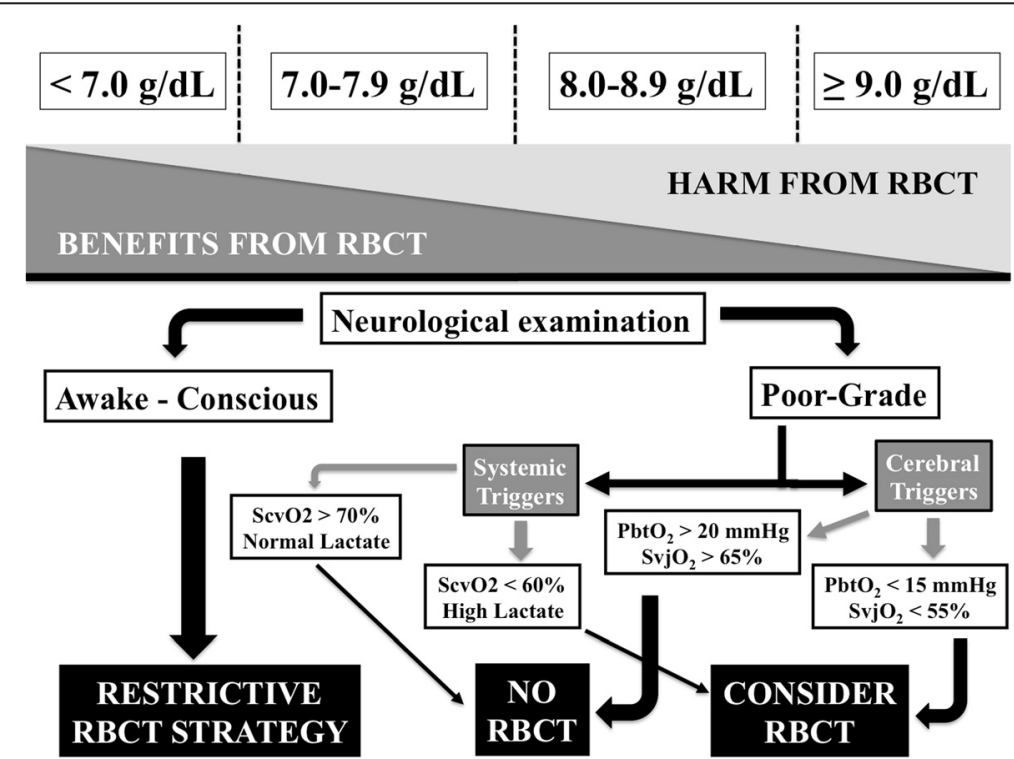

Fig. 3 The decision to administer red blood cell transfusions (RBCT) should take into consideration the potential benefits and harms of this intervention, according to different haemoglobin $(\mathrm{Hb})$ levels at which RBCT is initiated. In brain-injured patients, the RBCT strategy should be "restrictive" (if $\mathrm{Hb}$ is less than $7.0 \mathrm{~g} / \mathrm{dl}$ ) in awake and conscious patients. For poor-grade comatose patients, systemic (superior vena cava oxygen saturation $\left(\mathrm{ScVO}_{2}\right)$ or high lactate levels) or cerebral triggers (jugular vein oxygen saturation $\left(\mathrm{SvjO}_{2}\right)$ or brain tissue oxygen pressure $\left.\left(\mathrm{PbtO}_{2}\right)\right)$ could be used to guide RBC administration 
triggers, optimization of oxygen delivery to reach a mixed $\left(\mathrm{SvO}_{2}\right)$ or superior vena cava $\left(\mathrm{ScvO}_{2}\right)$ oxygen saturation $>70 \%$ using, amongst all potential interventions, also RBCT, as shown for the early management of sepsis [90], may be useful to improve brain oxygenation and overall outcome. As such, Gaieski et al. [91] showed that early hemodynamic optimization of patients after postanoxic brain injury using a target $\mathrm{ScvO}_{2}$ of $\geq 65 \%$ was associated with reduced mortality, although not statistically significant, when compared with historical controls $(10 / 20$ (50 \%) versus14/18 (78 \%), $p=0.15)$. Similarly, Walters et al. [92] showed a trend towards better neurological outcome in patients treated with such a therapeutic approach compared with historical controls (31\% versus $12 \%, p=0.08)$. Interestingly, $\mathrm{RBC}$ can significantly influence the microcirculation, where their altered morphology and deformability may impair local rheology and further enhance microvascular abnormalities associated with sepsis, particularly in those patients with normal baseline microvascular flow [93]. Similar results were also found for patients with elevated lactate levels [94]. Thus, using biomarkers of impaired oxygen tissue delivery could help to identify those patients who are more likely to benefit from RBCT because of inadequate systemic $\mathrm{DO}_{2}$, although no data are available on how these systemic "triggers" can guide RBCT specifically in brain-injured patients.

Specific "cerebral" triggers may be helpful and should include the invasive or non-invasive assessment of cerebral oxygenation (e.g., venous saturation in the jugular vein $\left(\mathrm{SvjO}_{2}\right), \mathrm{PbtO}_{2}$, or $\left.\mathrm{StO}_{2}\right)$ to individualize transfusion requirements, even though they may suffer technical limitations or poorly predict a "positive" response (e.g., improved oxygenation) to RBCT. Only patients with anemia (e.g., $\mathrm{Hb}<9-10 \mathrm{~g} / \mathrm{dl}$ ) and concomitant tissue hypoxia (e.g., $\mathrm{PbtO}_{2}<15-20 \mathrm{mmHg}, \mathrm{SvjO}_{2}<55 \%$ ) should be considered as potential candidates for RBCT. The main limitations of such an approach are that these oxygenation-monitoring devices are not available in all centers and some of them are costly and give information only for a very limited area of the brain [88]; it would thus be difficult to recommend the wide use of such tools in all poor-grade brain-injured patients. Importantly, RBCT is not the only therapeutic intervention that may improve cerebral oxygenation in such patients; as such, clinicians should rule out other possible causes for cerebral hypoperfusion (e.g., increased intracranial hypertension, severe hypocapnia, systemic hypotension) or hypoxia (e.g., seizures, hyperthermia, arterial hypoxemia) before considering RBCT in the management of such patients. Finally, patients may present with signs of low systemic $\mathrm{DO}_{2}$ (e.g., low $\mathrm{ScvO}_{2}$ ) and normal cerebral oxygenation (e.g., $\mathrm{PbtO}_{2}>20 \mathrm{mmHg}$ ). In this case, if the aim is to improve cerebral $\mathrm{DO}_{2}$, cerebral triggers should be preferred to target $\mathrm{Hb}$ levels in acute brain-injured patients, although this strategy may result in systemic hypoperfusion and non-cerebral organ dysfunction. Thus, decision to initiate RBCT in brain-injured patients remains a critical challenge for clinicians in the absence of specific monitoring tools.

Finally, future studies should also consider the use of $\mathrm{EPO}$ and its derivates to slowly increase $\mathrm{Hb}$ and minimize the risk of anemia and exposure to RBCT in such patients. Moreover, EPO may exert dose-dependent neuroprotective actions, including anti-inflammatory, anti-apoptotic, and endothelial effects, when administered in the early phase after injury, at least in experimental models $[95,96]$. In the human setting, a small retrospective study showed some potential benefits for erythropoiesis-stimulating agents after TBI [97], while significant concerns about the increased risk of thrombotic events or even mortality have been raised in patients with stroke or polytrauma $[98,99]$. In a recent trial, Robertson et al. [86] showed no significant benefits on neurological recovery of EPO compared with placebo in 200 severe TBI patients. In another randomized study, Nichol et al. [100] showed that EPO given once per week for a maximum of three doses $(n=308)$ did not reduce the proportion of patients with poor neurological outcome compared with placebo $(n=298,44$ versus $45 \%, p=0.90)$. Unfortunately, the $\mathrm{RBCT}$ requirement was similar between groups, although the amount of RBC packs transfused over the study period was not specifically reported in this study.

\section{Conclusions}

Anemia is common among brain-injured patients and associated with worse outcome. RBC transfusions may rapidly increase $\mathrm{Hb}$ levels in such patients but are also associated with poor outcome and complications. Few clinical studies on the optimal transfusion strategy have been performed in this setting and are biased by significant confounders. A restrictive RBCT policy should be implemented in such patients, in particular if they are awake and conscious, unless poor tolerance to anemia (e.g. ischemic heart disease) are present. An individualized transfusion strategy is warranted in poor-grade patients, using different tools to detect global/cerebral hypoxia, although the reliability of such approach need to be adequately validated.

\section{Abbreviations}

$\mathrm{AJDO}_{2}$ : arterio-jugular oxygen; $\mathrm{CaO}_{2}$ : arterial oxygen content; $\mathrm{CBF}$ : cerebral blood flow; $\mathrm{Cl}$ : confidence interval; $\mathrm{CMRO}_{2}$ : cerebral metabolic rate of oxygen; $\mathrm{DO}_{2}$ : oxygen delivery; EPO: erythropoietin; Hb: hemoglobin; HIF: hypoxia-inducible factor; ICH: intracranial hemorrhage; ICU: intensive care unit; LPR: lactate to pyruvate ratio; NO: nitric oxide; OR: odds ratio; $\mathrm{PbtO}_{2}$ : brain tissue oxygen pressure; RBC: red blood cells; RBCT: red blood cell transfusion; $\mathrm{SAH}$ : subarachnoid hemorrhage; $\mathrm{ScvO}_{2}$ : vena cava oxygen saturation; $\mathrm{StO}_{2}$ : brain oxygen saturation; $\mathrm{SvjO}_{2}$ : venous saturation in the jugular vein; TBI: traumatic brain injury. 


\section{Competing interests}

The authors declare that they have no competing interests.

\section{Authors' contributions}

$\mathrm{CL}$ and FST conceived the idea of the review; $\mathrm{CL}, \mathrm{PB}, \mathrm{IAC}$, and FST participated in the design of the manuscript; $C L, P B, I A C$, and FST carried out the literature search. All the authors drafted the present manuscript; $C L, P B$, IAC, and FST revised the manuscript. All authors read and approved the final version of the manuscript.

\section{Author details}

'Department of Intensive Care, Hôpital Erasme, Université Libre de Bruxelles (ULB), Route de Lennik 808, 1070 Brussels, Belgium. ${ }^{2}$ Laboratoire de Médecine Expérimentale, Université Libre de Bruxelles (ULB) - Unité 222, CHU Charleroi (Hôpital André Vésale), Rue de Gozée 706, Montigny-Le-Tilleul, Belgium. ${ }^{3}$ Department of Anaesthesiology and Critical Care, Grenoble University Hospital, Hôpital Albert Michallon, Avenue Maquis du Grésivaudan, Grenoble F-38043, France. ${ }^{4}$ Grenoble Neurosciences Institute, Grenoble Alpes University, Grenoble F-38043, France.

\section{Published online: 17 June 2016}

\section{References}

1. Walsh TS, Lee RJ, Maciver CR, Garrioch M, Mackirdy F, Binning AR, et al. Anemia during and at discharge from intensive care: the impact of restrictive blood transfusion practice. Intensive Care Med. 2006;32(1):100-9.

2. Vincent $J-L$ et al. Anemia and blood transfusion in critically ill patients. JAMA. 2002:288(12):1499-507.

3. Corwin HL, Surgenor SD, Gettinger A. Transfusion practice in the critically ill. Crit Care Med. 2003;31(12 Suppl):S668-71.

4. Scharte M, Fink MP. Red blood cell physiology in critical illness. Crit Care Med. 2003;31(12 Suppl):S651-7.

5. Prakash D. Anemia in the ICU: anemia of chronic disease versus anemia of acute illness. Crit Care Clin. 2012;28(3):333-43.

6. Ranasinghe T, Freeman WD. ICU vampires and anemia. Crit Care. 2015:19(1):25.

7. Walsh TS, Saleh EE. Anaemia during critical illness. Br J Anaesth. 2006;97(3):278-91.

8. Hao Z, Wu B, Wang D, Lin S, Tao W, Liu M. A cohort study of patients with anemia on admission and fatality after acute ischemic stroke. J Clin Neurosci. 2013;20(1):37-42.

9. Habler OP, Kleen MS, Hutter JW, Podtschaske AH, Tiede M, Kemming Gl, et al. Effects of hyperoxic ventilation on hemodilution-induced changes in anesthetized dogs. Transfusion. 1998;38(2):135-44.

10. Hare GM, Tsui AK, McLaren AT, Ragoonanan TE, Yu J, Mazer CD. Anemia and cerebral outcomes: many questions, fewer answers. Anesth Analg. 2008; 107(4):1356-70.

11. Weiskopf RB, Feiner J, Hopf H, Viele MK, Watson JJ, Lieberman J, et al. Heart rate increases linearly in response to acute isovolemic anemia. Transfusion. 2003:43(2):235-40.

12. Madjdpour C, Spahn DR. Allogeneic red blood cell transfusion: physiology of oxygen transport. Best Pract Res Clin Anaesthesiol. 2007;21(2):163-71.

13. Spahn DR, Leone BJ, Reves JG, Pasch T. Cardiovascular and coronary physiology of acute isovolemic hemodilution: a review of nonoxygencarrying and oxygen-carrying solutions. Anesth Analg. 1994;78(5):1000-21.

14. Toy P, Feiner J, Viele MK, Watson J, Yeap H, Weiskopf RB. Fatigue during acute isovolemic anemiain healthy, resting humans. Transfusion. 2000:40(4):457-60.

15. McLaren AT, Mazer CD, Zhang H, Liu E, Mok L, Hare GM. A potential role for inducible nitric oxide synthase in the cerebral response to acute hemodilution. Can J Anaesth. 2009;56(7):502-9.

16. Cabrales P, Tsai AG. Plasma viscosity regulates systemic and microvascular perfusion during acute extreme anemic conditions. Am J Physiol Heart Circ Physiol. 2006;291(5):H2445-52.

17. McLaren AT, Marsden PA, Mazer CD, Baker AJ, Stewart DJ, Tsui AK, et al. Increased expression of HIF-1alpha, nNOS, and VEGF in the cerebral cortex of anemic rats. Am J Physiol Regul Integr Comp Physiol. 2007;292(1):R403-14

18. Sargin D, Friedrichs $H$, El-Kordi A, Ehrenreich H. Erythropoietin as neuroprotective and neuroregenerative treatment strategy: comprehensive overview of 12 years of preclinical and clinical research. Best Pract Res Clin Anaesthesiol. 2010;24(4):573-94.
19. Weidemann A, Kerdiles YM, Knaup KX, Rafie CA, Boutin AT, Stockmann C, et al. The glial cell response is an essential component of hypoxia-induced erythropoiesis in mice. J Clin Invest. 2009;119(11):3373-83.

20. Weiskopf RB, Kramer JH, Viele M, Neumann M, Feiner JR, Watson JJ, et al. Acute severe isovolemic anemia impairs cognitive function and memory in humans. Anesthesiology. 2000;92(6):1646-52.

21. Weiskopf RB, Aminoff MJ, Hopf HW, Feiner J, Viele MK, Watson JJ, et al. Acute isovolemic anemia does not impair peripheral or central nerve conduction. Anesthesiology. 2003;99(3):546-51.

22. Walsh TS, Garrioch M, Maciver C, Lee RJ, MacKirdy F, McClelland DB, et al. Red cell requirements for intensive care units adhering to evidence-based transfusion guidelines. Transfusion. 2004:44(10):1405-11.

23. Taccone FS, Citerio G. Advanced monitoring of systemic hemodynamics in critically ill patients with acute brain injury. Neurocrit Care. 2014;21 Suppl 2:S38-63.

24. Ramaekers VT, Casaer P, Daniels H, Marchal G. The influence of blood transfusion on brain blood flow autoregulation among stable preterm infants. Early Hum Dev. 1992;30(3):211-20.

25. Bruder N, Cohen B, Pellissier D, Francois G. The effect of hemodilution on cerebral blood flow velocity in anesthetized patients. Anesth Analg. 1998; 86(2):320-4.

26. Salim A, Hadjizacharia P, DuBose J, Brown C, Inaba K, Chan L, et al. Role of anemia in traumatic brain injury. J Am Coll Surg. 2008;207(3):398-406.

27. Sekhon MS, McLean N, Henderson WR, Chittock DR, Griesdale DE. Association of hemoglobin concentration and mortality in critically ill patients with severe traumatic brain injury. Crit Care. 2012;16(4):R128.

28. Steyerberg EW, Mushkudiani N, Perel P, Butcher I, Lu J, McHugh GS, et al. Predicting outcome after traumatic brain injury: development and international validation of prognostic scores based on admission characteristics. PLoS Med. 2008:5(8):e165. discussion e165.

29. Van Beek JG, Mushkudiani NA, Steyerberg EW, Butcher I, McHugh GS, Lu J, et al. Prognostic value of admission laboratory parameters in traumatic brain injury: results from the IMPACT study. J Neurotrauma. 2007;24(2):315-28.

30. Duane TM, Mayglothling J, Grandhi R, Warrier N, Aboutanos MB, Wolfe LG, et al. The effect of anemia and blood transfusions on mortality in closed head injury patients. J Surg Res. 2008:147(2):163-7.

31. Robertson CS, Gopinath SP, Goodman JC, Contant CF, Valadka AB, Narayan RK. SjvO2 monitoring in head-injured patients. J Neurotrauma. 1995;12(5):891-6.

32. McIntyre LA, Fergusson DA, Hutchison JS, Pagliarello G, Marshall JC, Yetisir E, et al. Effect of a liberal versus restrictive transfusion strategy on mortality in patients with moderate to severe head injury. Neurocrit Care. 2006;5(1):4-9.

33. Sanchez-Olmedo Jl, Flores-Cordero JM, Rincon-Ferrari MD, Perez-Ale M, Munoz-Sanchez MA, Dominguez-Roldan JM, et al. Brain death after severe traumatic brain injury: the role of systemic secondary brain insults. Transplant Proc. 2005;37(5):1990-2.

34. Carlson AP, Schermer CR, Lu SW. Retrospective evaluation of anemia and transfusion in traumatic brain injury. J Trauma. 2006;61(3):567-71.

35. Griesdale DE, Sekhon MS, Menon DK, Lavinio A, Donnelly J, Robba C, et al. Hemoglobin area and time index above $90 \mathrm{~g} / \mathrm{L}$ are associated with improved 6-month functional outcomes in patients with severe traumatic brain injury. Neurocrit Care. 2015;23(1):78-84.

36. Utter GH, Shahlaie K, Zwienenberg-Lee M, Muizelaar JP. Anemia in the setting of traumatic brain injury: the arguments for and against liberal transfusion. J Neurotrauma. 2011:28(1):155-65.

37. Sahuquillo J, Poca MA, Garnacho A, Robles A, Coello F, Godet C, et al. Early ischaemia after severe head injury. Preliminary results in patients with diffuse brain injuries. Acta Neurochir (Wien). 1993;122(3-4):204-14.

38. Cruz J, Jaggi JL, Hoffstad OJ. Cerebral blood flow and oxygen consumption in acute brain injury with acute anemia: an alternative for the cerebral metabolic rate of oxygen consumption? Crit Care Med. 1993:21(8):1218-24

39. Cruz J, Hoffstad OJ, Jaggi JL. Cerebral lactate-oxygen index in acute brain injury with acute anemia: assessment of false versus true ischemia. Crit Care Med. 1994;22(9):1465-70

40. Oddo M, Levine JM, Kumar M, Iglesias K, Frangos S, Maloney-Wilensky E, et al. Anemia and brain oxygen after severe traumatic brain injury. Intensive Care Med. 2012:38(9):1497-504

41. Chang JJ, Youn TS, Benson D, Mattick H, Andrade N, Harper CR, et al. Physiologic and functional outcome correlates of brain tissue hypoxia in traumatic brain injury. Crit Care Med. 2009;37(1):283-90. 
42. Kramer AH, Zygun DA, Bleck TP, Dumont AS, Kassell NF, Nathan B. Relationship between hemoglobin concentrations and outcomes across subgroups of patients with aneurysmal subarachnoid hemorrhage. Neurocrit Care. 2009:10(2):157-65.

43. Le Roux PD. Anemia and transfusion after subarachnoid hemorrhage. Neurocrit Care. 2011;15(2):342-53.

44. Wartenberg KE, Schmidt JM, Claassen J, Temes RE, Frontera JA, Ostapkovich $\mathrm{N}$, et al. Impact of medical complications on outcome after subarachnoid hemorrhage. Crit Care Med. 2006;34(3):617-23. quiz 624.

45. Kramer AH, Gurka MJ, Nathan B, Dumont AS, Kassell NF, Bleck TP. Complications associated with anemia and blood transfusion in patients with aneurysmal subarachnoid hemorrhage. Crit Care Med. 2008:36(7):2070-5.

46. Naidech AM, Jovanovic B, Wartenberg KE, Parra A, Ostapkovich N, Connolly ES, et al. Higher hemoglobin is associated with improved outcome after subarachnoid hemorrhage. Crit Care Med. 2007;35(10):2383-9.

47. Oddo M, Milby A, Chen I, Frangos S, MacMurtrie E, Maloney-Wilensky E, et al. Hemoglobin concentration and cerebral metabolism in patients with aneurysmal subarachnoid hemorrhage. Stroke. 2009;40(4):1275-81.

48. Kurtz P, Schmidt JM, Claassen J, Carrera E, Fernandez L, Helbok R, et al. Anemia is associated with metabolic distress and brain tissue hypoxia after subarachnoid hemorrhage. Neurocrit Care. 2010;13(1):10-6.

49. Milionis H, Papavasileiou V, Eskandari A, D'Ambrogio-Remillard S, Ntaios G, Michel P. Anemia on admission predicts short- and long-term outcomes in patients with acute ischemic stroke. Int J Stroke. 2015;10(2):224-30.

50. Kellert L, Kloss M, Pezzini A, Metso TM, Metso AJ, Debette S, et al. Anemia in young patients with ischaemic stroke. Eur J Neurol. 2015;22(6):948-53.

51. Sico JJ, Concato J, Wells CK, Lo AC, Nadeau SE, Williams LS, et al. Anemia is associated with poor outcomes in patients with less severe ischemic stroke. J Stroke Cerebrovasc Dis. 2013;22(3):271-8.

52. Lasek-Bal A, Holecki M, Steposz A, Dulawa J. The impact of anemia on the course and short-term prognosis in patients with first ever ischemic stroke. Neurol Neurochir Pol. 2015;49(2):107-12.

53. Kellert L, Herweh C, Sykora M, Gussmann P, Martin E, Ringleb PA, et al Loss of penumbra by impaired oxygen supply? Decreasing hemoglobin levels predict infarct growth after acute ischemic stroke: Stroke: Relevant Impact of Hemoglobin, Hematocrit and Transfusion (STRAIGHT)-an observational study. Cerebrovasc Dis Extra. 2012;2(1):99-107.

54. Furlan JC, Fang J, Silver FL. Acute ischemic stroke and abnormal blood hemoglobin concentration. Acta Neurol Scand. 2015. Epub ahead of print.

55. Zeng YJ, Liu GF, Liu LP, Wang CX, Zhao XQ, Wang YJ. Anemia on admission increases the risk of mortality at 6 months and 1 year in hemorrhagic stroke patients in China. J Stroke Cerebrovasc Dis. 2014;23(6):1500-5.

56. Bussiere M, Gupta M, Sharma M, Dowlatshahi D, Fang J, Dhar R. Anaemia on admission is associated with more severe intracerebral haemorrhage and worse outcomes. Int J Stroke. 2015;10(3):382-7.

57. Diedler J, Sykora M, Hahn P, Heerlein K, Scholzke MN, Kellert L, et al. Low hemoglobin is associated with poor functional outcome after non-traumatic, supratentorial intracerebral hemorrhage. Crit Care. 2010; 14(2):R63

58. Kuramatsu JB, Gerner ST, Lucking H, Kloska SP, Schellinger PD, Kohrmann M, et al. Anemia is an independent prognostic factor in intracerebral hemorrhage: an observational cohort study. Crit Care. 2013;17(4):R148.

59. Kumar MA, Rost NS, Snider RW, Chanderraj R, Greenberg SM, Smith EE, et al. Anemia and hematoma volume in acute intracerebral hemorrhage. Crit Care Med. 2009;37(4):1442-7

60. Ameloot K, Genbrugge C, Meex I, Janssens S, Boer W, Mullens W, et al. Low hemoglobin levels are associated with lower cerebral saturations and poor outcome after cardiac arrest. Resuscitation. 2015;96:280-6.

61. Carson JL, Grossman BJ, Kleinman S, Tinmouth AT, Marques MB, Fung MK, et al. Red blood cell transfusion: a clinical practice guideline from the AABB. Ann Intern Med. 2012;157(1):49-58.

62. Marik PE, Corwin HL. Efficacy of red blood cell transfusion in the critically ill: a systematic review of the literature. Crit Care Med. 2008;36(9):2667-74.

63. Vamvakas EC, Blajchman MA. Transfusion-related immunomodulation (TRIM): an update. Blood Rev. 2007;21(6):327-48.

64. Li G, Rachmale S, Kojicic M, Shahjehan K, Malinchoc M, Kor DJ, et al. Incidence and transfusion risk factors for transfusion-associated circulatory overload among medical intensive care unit patients. Transfusion. 2011;51(2):338-43.
65. Benson AB, Moss M, Silliman CC. Transfusion-related acute lung injury (TRALI): a clinical review with emphasis on the critically ill. Br J Haematol. 2009;147(4):431-43.

66. Lelubre C, Vincent JL. Relationship between red cell storage duration and outcomes in adults receiving red cell transfusions: a systematic review. Crit Care. 2013:17(2):R66.

67. Bennett-Guerrero E et al. Evolution of adverse changes in stored RBCs. Proc Natl Acad Sci U S A. 2007;104(43):17063-8.

68. George ME, Skarda DE, Watts CR, Pham HD, Beilman GJ. Aggressive red blood cell transfusion: no association with improved outcomes for victims of isolated traumatic brain injury. Neurocrit Care. 2008;8(3):337-43.

69. Smith MJ, Stiefel MF, Magge S, Frangos S, Bloom S, Gracias V, et al. Packed red blood cell transfusion increases local cerebral oxygenation. Crit Care Med. 2005;33(5):1104-8.

70. Warner MA, O'Keeffe T, Bhavsar P, Shringer R, Moore C, Harper C, et al, Transfusions and long-term functional outcomes in traumatic brain injury. Neurosurg. 2010;113(3):539-46.

71. Zygun DA, Nortje J, Hutchinson PJ, Timofeev I, Menon DK, Gupta AK. The effect of red blood cell transfusion on cerebral oxygenation and metabolism after severe traumatic brain injury. Crit Care Med 2009;37(3):1074-8

72. Festic E, Rabinstein AA, Freeman WD, Mauricio EA, Robinson MT, Mandrekar J, et al. Blood transfusion is an important predictor of hospital mortality among patients with aneurysmal subarachnoid hemorrhage. Neurocrit Care. 2013;18(2):209-15.

73. Smith MJ, Le Roux PD, Elliott JP, Winn HR. Blood transfusion and increased risk for vasospasm and poor outcome after subarachnoid hemorrhage. J Neurosurg. 2004;101(1):1-7.

74. Tseng MY, Hutchinson PJ, Kirkpatrick PJ. Effects of fluid therapy following aneurysmal subarachnoid haemorrhage: a prospective clinical study. Br J Neurosurg. 2008;22(2):257-68.

75. Broessner G, Lackner P, Hoefer C, Beer R, Helbok R, Grabmer C, et al. Influence of red blood cell transfusion on mortality and long-term functional outcome in 292 patients with spontaneous subarachnoid hemorrhage. Crit Care Med. 2009;37(6):1886-92.

76. Kurtz P, Helbok R, Claassen J, Schmidt JM, Fernandez L, Stuart RM, et al. The effect of packed red blood cell transfusion on cerebral oxygenation and metabolism after subarachnoid hemorrhage. Neurocrit Care. 2016;24(1): 118-21.

77. Dhar R, Zazulia AR, Videen TO, Zipfel GJ, Derdeyn CP, Diringer MN Red blood cell transfusion increases cerebral oxygen delivery in anemic patients with subarachnoid hemorrhage. Stroke. 2009;40(9):3039-44

78. Dhar R, Scalfani MT, Zazulia AR, Videen TO, Derdeyn CP, Diringer MN. Comparison of induced hypertension, fluid bolus, and blood transfusion to augment cerebral oxygen delivery after subarachnoid hemorrhage. J Neurosurg. 2012;116(3):648-56.

79. Sheth KN, Gilson AJ, Chang Y, Kumar MA, Rahman RM, Rost NS, et al. Packed red blood cell transfusion and decreased mortality in intracerebral hemorrhage. Neurosurgery. 2011;68(5):1286-92.

80. Mohamed W, Reddy S, Sivakumar S. Blood transfusion does not improve outcomes in patients with spontaneous intracerebral hemorrhage. Neurology. 2014;82(Suppl):143.

81. Chang TR, Boehme AK, Aysenne A, Albright KC, Burns C, Beasley TM, et al. Nadir hemoglobin is associated with poor outcome from intracerebral hemorrhage. Springerplus. 2013;2:379.

82. Kellert L, Schrader F, Ringleb P, Steiner T, Bosel J. The impact of low hemoglobin levels and transfusion on critical care patients with severe ischemic stroke: STroke: RelevAnt Impact of HemoGlobin, Hematocrit and Transfusion (STRAIGHT)-an observational study. J Crit Care. 2014;29(2):236-40

83. Lacroix J, Hebert PC, Hutchison JS, Hume HA, Tucci M, Ducruet T, et al. Transfusion strategies for patients in pediatric intensive care units. N Engl J Med. 2007;356(16):1609-19.

84. Fluckiger C, Bechir M, Brenni M, Ludwig S, Sommerfeld J, Cottini SR, et al. Increasing hematocrit above $28 \%$ during early resuscitative phase is not associated with decreased mortality following severe traumatic brain injury. Acta Neurochir (Wien). 2010;152(4):627-36.

85. Naidech AM, Shaibani A, Garg RK, Duran IM, Liebling SM, Bassin SL, et al. Prospective, randomized trial of higher goal hemoglobin after subarachnoid hemorrhage. Neurocrit Care. 2010;13(3):313-20. 
86. Robertson CS, Hannay HJ, Yamal JM, Gopinath S, Goodman JC, Tilley BC, et al. Effect of erythropoietin and transfusion threshold on neurological recovery after traumatic brain injury: a randomized clinical trial. JAMA. 2014:312(1):36-47.

87. Sena MJ, Rivers RM, Muizelaar JP, Battistella FD, Utter GH. Transfusion practices for acute traumatic brain injury: a survey of physicians at US trauma centers. Intensive Care Med. 2009;35(3):480-8.

88. Kramer AH, Diringer MN, Suarez JI, Naidech AM, Macdonald LR, Le Roux PD. Red blood cell transfusion in patients with subarachnoid hemorrhage: a multidisciplinary North American survey. Crit Care. 2011;15(1):R30.

89. Vincent JL. Indications for blood transfusions: too complex to base on a single number? Ann Intern Med. 2012;157(1):71-2.

90. Rivers E, Nguyen B, Havstad S, Ressler J, Muzzin A, Knoblich B, et al. Early goal-directed therapy in the treatment of severe sepsis and septic shock. N Engl J Med. 2001;345(19):1368-77.

91. Gaieski DF, Band RA, Abella BS, Neumar RW, Fuchs BD, Kolansky DM, et al. Early goal-directed hemodynamic optimization combined with therapeutic hypothermia in comatose survivors of out-of-hospital cardiac arrest. Resuscitation. 2009;80(4):418-24.

92. Walters EL, Morawski K, Dorotta I, Ramsingh D, Lumen K, Bland D, et al. Implementation of a post-cardiac arrest care bundle including therapeutic hypothermia and hemodynamic optimization in comatose patients with return of spontaneous circulation after out-of-hospital cardiac arrest: a feasibility study. Shock. 2011;35(4):360-6.

93. Piagnerelli M, Boudjeltia KZ, Brohee D, Piro P, Carlier E, Vincent JL, et al. Alterations of red blood cell shape and sialic acid membrane content in septic patients. Crit Care Med. 2003;31(8):2156-62.

94. Mazza BF, Freitas FG, Barros MM, Azevedo LC, Machado FR. Blood transfusions in septic shock: is $7.0 \mathrm{~g} / \mathrm{dL}$ really the appropriate threshold? Rev Bras Ter Intensiva. 2015;27(1):36-43.

95. Peng W, Xing Z, Yang J, Wang Y, Wang W, Huang W. The efficacy of erythropoietin in treating experimental traumatic brain injury: a systematic review of controlled trials in animal models. J Neurosurg. 2014;121(3):653-64.

96. Bouzat P, Millet A, Boue Y, Pernet-Gallay K, Trouve-Buisson T, Gaide-Chevronnay L, et al. Changes in brain tissue oxygenation after treatment of diffuse traumatic brain injury by erythropoietin. Crit Care Med. 2013;41(5):1316-24.

97. Talving P, Lustenberger T, Kobayashi L, Inaba K, Barmparas G, Schnuriger B, et al. Erythropoiesis stimulating agent administration improves survival after severe traumatic brain injury: a matched case control study. Ann Surg. 2010;251(1):1-4.

98. Corwin HL, Gettinger A, Fabian TC, May A, Pearl RG, Heard S, et al. Efficacy and safety of epoetin alfa in critically ill patients. N Engl I Med. 2007;357(10):965-76.

99. Ehrenreich H, Weissenborn K, Prange H, Schneider D, Weimar C, Wartenberg K, et al. Recombinant human erythropoietin in the treatment of acute ischemic stroke. Stroke. 2009;40(12):e647-56.

100. Nichol A, French C, Little L, Haddad S, Presneill J, Arabi Y, et al. Erythropoietin in traumatic brain injury (EPO-TBI): a double-blind randomised controlled trial. Lancet. 2015;386(10012):2499-506. 